Por la ventana del tiempo. Algunos casos de apropiacionismo en el arte argentino Soledad Sobrino Boletín de Arte (N. $\left.{ }^{\circ} 19\right)$, e012, septiembre 2019. ISSN 2314-2502

https://doi.org/10.24215/23142502e012

http://papelcosido.fba.unlp.edu.ar/ojs/index.php/boa

Facultad de Bellas Artes. Universidad Nacional de La Plata

La Plata. Buenos Aires. Argentina

\title{
POR LA VENTANA DEL TIEMPO ALGUNOS CASOS DE APROPIACIONISMO EN EL ARTE ARGENTINO
}

\section{THROUGH THE WINDOW OF TIME \\ SOME CASES OF APPROPRIATION IN ARGENTINE ART}

\author{
Soledad Sobrino \\ sole.sobrino9@gmail.com
}

Facultad de Filosofía y Letras. Universidad de Buenos Aires / Instituto de Altos Estudios Sociales. Universidad Nacional de San Martín. Argentina

Recibido: 11/3/2019

Aceptado: 19/6/2019

RESUMEN

El siguiente artículo indaga en un fenómeno particular del arte moderno y contemporáneo argentino: la apropiación, por parte de ciertos artistas, de obras pictóricas nacionales del pasado para producir las propias. Si bien se reconoce a la cita como un elemento constitutivo de la historia del arte, para este análisis partiremos de la hipótesis de que la apropiación de obras nacionales es particularmente frecuente en momentos de inestabilidad política y social, y que los artistas parten de ellas para abrir nuevos puntos de vista respecto al pasado. Se analizarán puntualmente algunos casos de apropiación iconográfica de la obra sin pan y sin trabajo (1894), de Ernesto de la Cárcova, realizados durante el siglo XX. Finalmente, se hará una primera aproximación al apropiacionismo como operatoria del arte contemporáneo, donde esta misma obra resulta reinterpretada con frecuencia.

PALABRAs Clave

Arte argentino; apropiacionismo; museo imaginario; arte moderno; arte contemporáneo
ABStRACT

The following research is about a specific phenomenon in modern and contemporary art: some Argentine artists appropriate previous national paintings to create their own works. Despite referencing is a constituent item in the history of art, in the present article we argue that the appropriation of national paintings is more frequent in social and political unstable moments. Artists, in those contexts, allude to this previous and canonic works in order to show new possible points of view about the national past. We are going to analyze some cases of appropriation of the painting sin pan y sin trabajo [Without bread and without work] (1894), by Ernesto de la cárcova, executed in the twentieth century. Finally, we are going to establish a first approach to the appropriation in Argentine contemporary art, time in which de la Carcova's painting is frequently recreated.

KEYWORDS

Appropriationism; imaginary museum; Argentine art; modern art; contemporary art 
Un haz de luz entra por una ventana. Ilumina un interior en penumbras y traza una diagonal en la que se recorta el perfil de un hombre y de una mujer. El resto de los objetos que conforman ese interior es mínimo: una mesa, unas sillas, una viga que permite adivinar que la construcción tiene techo de madera, un paño blanco que enmarca la ventana. Nuestra mirada queda sujeta en el centro de la composición, donde se condensan tanto el valor lumínico como el semántico; en los dos rostros de perfil ajenos al espectador, ella aparentemente absorta en sus pensamientos, él concentrado en lo que pasa a través del vidrio. El paisaje al que se enfrentan sus ojos se compone de edificios altos y chimeneas sin humo, delante de las que se reúne un grupo de policías a caballo.

Esta fábrica cerrada a la que el trabajador no puede acercarse a cumplir sus tareas ha transformado a Sin pan y sin trabajo, de forma casi unánime, en «el primer cuadro de tema obrero con intención de crítica social en el arte argentino» (Malosetti Costa, 2010, p. 426). La pintura fue iniciada por Ernesto de la Cárcova en Roma, terminada en 1893 en Buenos Aires y expuesta por primera vez en 1894 en el 2. Salón del Ateneo con excelente repercusión. Se trataba de un contexto bastante diferente del europeo, al que el artista había tenido la posibilidad de acercarse para aprender el oficio de pintor. Para 1880 los temas naturalistas finiseculares eran de circulación corriente en los salones del viejo continente y se había abandonado parte del tinte crítico en pos de un interés por competir ante las composiciones más académicas. Por su parte, en la Argentina el campo plástico estaba en incipiente formación, a la par que la afluencia inmigratoria no paraba de crecer y empezaba a tener sus efectos secundarios. Laura Malosetti Costa (2001) señala la enorme fuerza expresiva y la contundente denuncia social que contiene este cuadro, a las que se suma una búsqueda de formas que dejen atrás las referencias románticas y la exaltación al pasado clásico. La composición está atravesada por múltiples diagonales que acentúan el equilibrio inestable de la silla de este hombre que - puño cerrado y hoz en la mesa- mira una fábrica por la ventana negándonos su rostro. Los colores de tono bajo y las sombras profundas intensifican el dramatismo y la incertidumbre de la que parecen presos los personajes: toda la escena presenta un efecto de contraluz que enfatiza los detalles y nos invita a detenernos en cada uno. ¿Cómo no mirar la fuerza de esos dedos aferrados a la ventana? ¿Y cómo no detenerse en esas otras manos, desdibujadas, curvadas, suaves, que sostienen un bebé dormido en brazos? ¿Cómo no escuchar el golpe de ese puño en la mesa, cerrado en su propio rencor, mientras las herramientas descansan al lado, iluminadas, filosas, agudas?

El presente trabajo se enmarca en un interés específico por la recurrencia de ciertos artistas a aludir explícitamente a imágenes del pasado para producir las propias. Nos referimos en esta instancia a ciertos juegos que se establecen con la memoria visual colectiva al articular diálogos directos entre lo que vemos y aquello que conforma nuestro archivo mental. ${ }^{1}$ Este juego puede adoptar diversas formas, que van desde las simples alusiones o citas hasta una operatoria -que se puede englobar bajo el título de apropiacionista- a través de la cual los artistas recrean por completo ciertas imágenes pero sostienen sus principales elementos iconográficos, al punto tal de hacerlas inseparables de su matriz original. En la Argentina, de entre todas las pinturas posibles, es notable cómo los artistas recurren a Sin pan y sin trabajo: ese puño cerrado, esas herramientas dormidas y ese cuerpo que no puede contenerse en su lugar condensan una tensión aparentemente dúctil para dirigirse indistintamente hacia una fábrica cerrada 0 a cualquier otra injusticia nacional.

Georges Didi-Huberman (2017) se ha adentrado en la temática de las sublevaciones y explica que las mismas «suponen una solidaridad muy profunda que une a los protagonistas, con sus duelos y sus deseos, pero que también hace confluir las épocas por medio de las imágenes» (p. 85). De allí parte - siguiendo el precepto warburgiano de que existen gestos de larga duración, que perviven en las formas de la cultura humana- para encontrar heterogéneas manifestaciones visuales en las que la fuerza de la memoria inflama un deseo de rebelión. Para el

1 Al hablar de archivo mental pensamos junto con Hal Foster (2004) en aquella estructura de la memoria que conformó el sistema de arte moderno y que rige en gran medida -aún hoy- nuestros modos de ver y pensar el arte. 
autor, las imágenes en las que se evidencia de manera más nítida la sublevación son aquellas en las que se levantan superficies: almohadas que chocan y que hacen volar sus plumas, el salto de un niño, una bandera que se iza, una sábana que se drapea hacia arriba con el viento. En Sin pan y sin trabajo el puño, en lugar de levantarse en señal de rebelión, se estrella hacia abajo en un quejido. El que se levanta en cambio es el cuerpo de la silla, en un arrebato que se aplicó en estos 134 años a distintas fábricas cerradas, al despido masivo por parte de una empresa, al vaciamiento cultural por parte del Estado, a la desesperación provocada por la crisis de 2001. Distintos paisajes se han configurado como fondo para esa ventana, sin alterar el gesto de indignación de quien se asoma por ella. ¿Qué circunstancias habrán hecho de esta obra una imagen tan pregnante para nuestra memoria cultural?

Por un lado, debe destacarse el gran protagonismo que tiene la presencia física de la pintura original, ubicada dentro del Museo Nacional de Bellas Artes (MNBA), en el centro de la sala de Arte Argentino del siglo XIX. La importancia que tuvo la llamada generación del ochenta para la identidad pictórica nacional en el contexto de su incipiente formación, ha hecho de la obra de De la Cárcova y de algunas producciones contemporáneas a ella hitos de nuestra historia del arte, que descansan en su mayoría juntas (y auráticas) en la misma sala de este importante centro legitimador. Por otro lado, existe también una circulación paralela de esas imágenes: nos referimos aquí a la difusión que han tenido en catálogos, tarjetas, postales, reproducciones, láminas, estudios académicos, acervos digitales, archivos virtuales y manuales escolares. Esta circulación paralela de las imágenes conforma para cada cultura lo que el teórico francés André Malraux (1956) definió como un museo imaginario, una ampliación de los espacios físicos que funciona en nuestra memoria y que se construye a partir de subjetividades y selectividades.

El texto El museo imaginario (1956), de Malraux, es una reflexión acerca del papel activo del museo como marco de nuestra comprensión de las imágenes, como ente que separa las obras de su contexto original en la acción de reunirlas y confrontarlas. Pero al hablar de museo, como ya se dio a entender, Malraux no solo se ocupó de los espacios físicos que albergan obras, sino también - y sobre todo- de aquellos museos mentales de cada cultura, que se constituyen a partir de la disponibilidad real de obras y también de fotos y reproducciones de otras piezas (a las que muchas veces no se tiene acceso físico). Esto se hace especialmente visible en el caso latinoamericano, cuyo territorio implica una geografía tan alejada de muchas de las grandes obras que conforman el relato canónico de la historia del arte occidental. Las reproducciones en estas latitudes funcionan como únicas fuentes de conocimiento, pese a que se aplanan muchas de las cualidades corpóreas originales. Si bien en ningún momento Malraux (1956) deja de lado que las obras reproducidas pierden algunas particularidades y se homogeneizan generando una suerte de «escuela ficticia de los estilos» (p. 22), también entiende que es la reproducción la que habilita la asociación entre imágenes, lo que expande el museo indefinidamente. En este sentido, parece encontrar una cualidad positiva en donde uno de sus más grandes influyentes vaticinaba una inevitable pérdida de la tradición: para Walter Benjamin [1936] (2002), la reproducción mecánica provoca la destrucción del aura, mientras que para Malraux (1956) esta destrucción es la que brinda los medios para, en la reciente lectura de Hal Foster (2004), «reunir los pedazos rotos de la tradición de estilos globales: un nuevo museo sin muros cuyo sujeto es la Familia del Hombre» (p. 78).

Con estas ideas presentes, en las siguientes páginas nos adentraremos en la producción de algunos artistas que, en distintos momentos de nuestra historia más reciente, escogieron vincularse de forma directa con la pintura sin pan y sin trabajo. Estos serán simplemente algunos casos que permiten dar cuenta de la centralidad de esta pieza en el museo imaginario argentino, que parece reactivarse en momentos de alta sensibilidad política como catalizadora de los reclamos más legítimos de la sociedad. 


\section{Del otro lado de la ventana: Antonio Berni (1934)}

Antonio Berni (1905-1981) se formó en su Rosario natal, donde obtuvo una beca en 1925 que le permitió viajar a Europa y concurrir a los ineludibles talleres parisinos de André Lhote y Othon Friesz. Luego de un período de intenso aprendizaje, que coincidió con la estadía de otros incipientes artistas argentinos del llamado Grupo de París, regresó a la Argentina en 1930, inmerso en formas y contenidos nuevos. Pero esos años no solo fueron de aprendizaje artístico: Berni estuvo en contacto con la partidaria pintura surrealista y metafísica; sostuvo además un acercamiento a las ideas anticolonialistas y un diálogo fluido con muchos intelectuales comunistas.

Como la mayor parte de los artistas que pasaron por Europa en la primera posguerra, los cambios que se evidencian en la obra de Berni de estos años se vinculan con un acercamiento a un nuevo método de expresión que - atravesado por las enseñanzas de los modernismos, las primeras vanguardias históricas y la llamada Escuela de París- permitiera dejar ver el dolor y la crisis que la sociedad mundial estaba experimentando. En este contexto, que Jean Cocteau entendió como una vuelto al orden, se inserta casi la totalidad del arte europeo de entreguerras (Babino, 2010). La producción de los artistas latinoamericanos, por su parte, debe leerse atravesada por esta complejidad y el particular contexto en el que cada uno se insertó al regresar.

Instalado nuevamente en su ciudad de origen, Berni viró con rapidez hacia un realismo social que acompañara la línea política impuesta por el Partido Comunista, al que se había afiliado en 1931. La crisis internacional de 1929, superpuesta a la crisis nacional y al breve pero intenso contacto con el revolucionario mexicano David Alfaro Siqueiros — que visitó la Argentina en 1933- fueron factores que influyeron en la creación de la serie de grandes obras narrativas de Berni de la década de los treinta: Desocupados (1934), Manifestación (1934), Chacareros (1935) y Medionoche en el mundo (1936-37). Quienes han analizado en profundidad estas obras de gran tamaño convergen en que la falta de muros reales podría haber impulsado la elección de una suerte de muralismo móvil — de materialidad frágil y fuerte connotación trabajadora——2 que permitiera trasladar los lienzos acompañando las marchas obreras. Pero salta a la vista que las obras de esta década, ante todo por su ubicación actual, no lograron escapar a la cualidad burguesa del cuadro de caballete. Incluso, aclara Roberto Amigo (2010b), el hecho de que fueran enviadas al salón establecería un retroceso expositivo a las grandes telas de asunto histórico que la modernización plástica había rechazado (como, justamente, Sin pan y sin trabajo).

Muchos autores han leído Manifestoción como una recuperación de la pintura de Ernesto de la Cárcova, ante todo por la consigna que reza el único cartel que se lee entre la multitud. Salta a la vista, sin embargo, que la escena dista mucho de la soledad y quietud de la casa del obrero decimonónico. Por el contrario, parece ubicar al espectador del otro lado de la ventana enfrentado al conjunto de individuos que colman las calles en pleno reclamo. El puño cerrado, esa señal de "pérdida» (Didi-Huberman, 2017) que siempre precede a la acción, ya dio paso en esta pintura a la expresión en masa: el levantamiento se evidencia en la pancarta con la leyenda "pan y trabajo», también en el puño de un trabajador con sombrero, y sobre todo en la mirada de dos de los personajes que se sitúan en primer plano, uno a cada lado de la composición. Y si bien se trata de un reclamo de validez mundial que puede fácilmente desestimar la referencia, consideraremos que la trascendencia de la pintura original logra trazar un vínculo directo con la de Berni.

Una de las razones más probables de que la referencia a De la Cárcova haya sido intencional es que la obra de Berni abreva también de otras fuentes visuales. Probablemente la más conocida sean las fotografías que el propio artista tomó en Rosario o recortó de la prensa, en las que se basó para realizar los rostros. Asimismo, en esas miradas que se dirigen a algún punto

2 Todas estas obras fueron realizadas a partir piezas de yute cosido o tela de arpillera tomada de sacos de azúcar de gran formato. 
alto fuera de la escena, Guillermo Fantoni (2017) ha identificado la participación de un posible orador, presente en un pequeño grabado de Berni y del cual no quedaron registros.

Al adentrarse en la carga retórica de esta pintura, Amigo (2017) señala que Manifestoción se aleja del discurso heroico presente en imágenes contemporáneas de otros artistas y se desplaza a la desesperanza consciente de los trabajadores, lo cual - podemos agregar- ubicaría la escena en un registro más similar al decimonónico. Pero el mismo autor realiza también otra lectura más compleja, vinculada a una autocrítica de la dirección comunista (incapaz de posicionarse como el partido modelo para el proletariado) y una crítica a la comunidad católica, movilizada en forma masiva en 1934 por el Congreso Eucarístico Internacional. Llega a esta última conclusión por considerar que Monifestación se trata también de la apropiación de un grabado del artista belga Víctor Delhez, quien interpretó en clave religiosa un pasaje de Las Flores del Mol (1857), de Charles Baudelaire. Unos meses antes de la creación del cuadro, el diario La Prensa había publicado dicha ilustración, en la que una procesión de personajes ciegos avanzaba mostrando en primer plano un conjunto de ojos vacíos, similares a los que Berni retrató en su lienzo. Ante esta referencia, Amigo (2017) interpreta que el mensaje es muy claro: «la salvación debe encontrarse en el puño cerrado del obrero, no en la mirada de cordero hacia lo alto» (p. 38).

Del conjunto de rostros desesperanzados se destaca el centro compositivo, compartido por el hombre trabajador, la mujer y el niño en brazos. Berni incorpora múltiples referencias visuales que lo ayudan a complejizar la escena colectiva de reclamo, pero mantiene presente la alusión a $\sin$ pan y sin trabajo. Esta se extiende del cartel que manifiesta el reclamo hacia esta familia que ya no contempla el presente con una mesa de por medio, sino que avanzan de pie, caminando entre la multitud [Figuras 1 y 2 ].

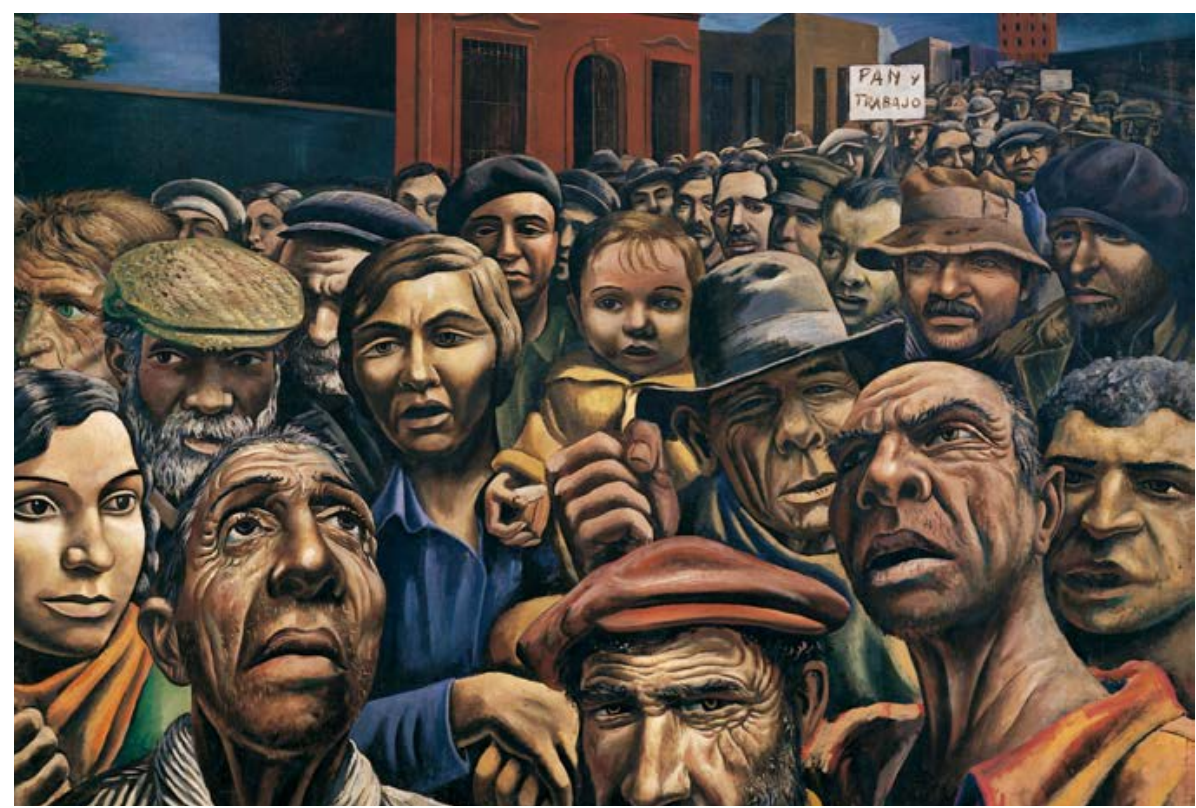

Figura 1. Antonio Berni, Manifestoción (1934). Colección Museo de Arte Latinoamericano de Buenos Aires (MALBA), Fundación Costantini 


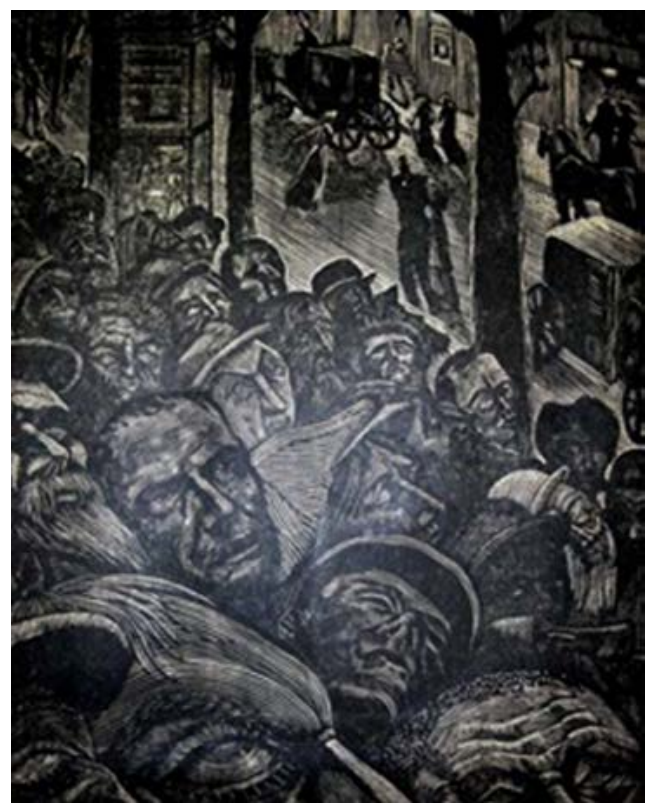

Figura 2. Víctor Delhez, Los vengadores (4 de julio de 1933). Sin datos

Del otro lado de la mirada: Carlos Alonso, 1966-1968

Así como en los años treinta la mayoría de los artistas del Grupo de París se encontró en una encrucijada política que los hizo meditar seriamente sobre el camino a seguir en la representación visual, hacia finales de la década de los sesenta se dio una coyuntura histórica similar. A la Revolución cubana desatada entre 1953 y 1959 se sumó el triunfo de la Unidad Popular (UP) en Chile en 1970, dos hechos de gran relevancia que hicieron que América Latina palpitara una experiencia socialista continental inminente. En ese contexto, al que se sumaron hechos internacionales como la intervención de Estados Unidos en la guerra de Vietnam, la cadena de protestas de mayo de 1968 y la primavera de Praga, muchos artistas tanto en Argentina como en otros países vecinos se preguntaron por la eficacia de la acción artística ante las necesidades políticas que planteaba el presente (Marchesi, 2010). Algunos, como León Ferrari o Luis Felipe Noé, propusieron un abandono total del arte «en busca de posibilidades de acción ideológica que ellos entendían más eficaces» (Marchesi, 2014, p. 408), otros se mantuvieron dentro del plano de la figuración, virando sus producciones hacia una temática reflexiva que transparentara su posición frente a los hechos históricos, en un planteo similar al del realismo socialista de la década de los treinta.

En medio de esta disyuntiva, el mendocino Carlos Alonso comenzó a trabajar en algunas obras de fuerte carácter crítico hacia la realidad política y económica predominantes. La obra de Alonso es habitualmente incluida en las vertientes neofigurativas argentinas que desestructuraron la representación con la gestualidad del informalismo, creando una suerte de Nuevo Realismo en el que conviven imágenes simultáneas con rupturas de plano y color (Alonso \& Cuello, 2018). En los breves años que separaron 1965 de 1970 Alonso dejó establecido su propio estilo: incursionó e incorporó la técnica del colloge, y encaró diversos trabajos - muchos inspirados en obras literarias, como El Matodero (1966), de Esteban Echeverría, o la Divino Comedia (1968), de Dante Alighieri- en los que configuró una línea temática continua entre el cuerpo, la carne, la violencia y la propia historia del arte. En este contexto, surgieron dos de sus series más importantes: una referida a sin pan y sin trabajo, y otra inspirada en la muerte de Ernesto Che Guevara. El abatimiento del revolucionario en 1967 debe haber resultado particularmente llamativo para Alonso, no solo por la conmoción ideológica que generó en nuestro país, sino también por las referencias directas a importantes pinturas históricas que evidenciaron las fotografías de su cuerpo muerto. Trascendió entonces la similitud de algunas de las tomas con el Cristo muerto (1480), de Andrea Mantegna, y con Lo lección de Anatomía del Dr. Nicoloes Tulp (1632), de Rembrandt, dos fuentes de las que el artista abrevó para elaborar 
una compleja serie en la que se mezclan la asepsia médica y la investidura militar. Estas obras serían solo las primeras de numerosas posteriores, en las que las referencias se desplazaron hacia las figuras de referentes artísticos como Vincent van Gogh, Lino Enea Spilimbergo o Pierre-Auguste Renoir.

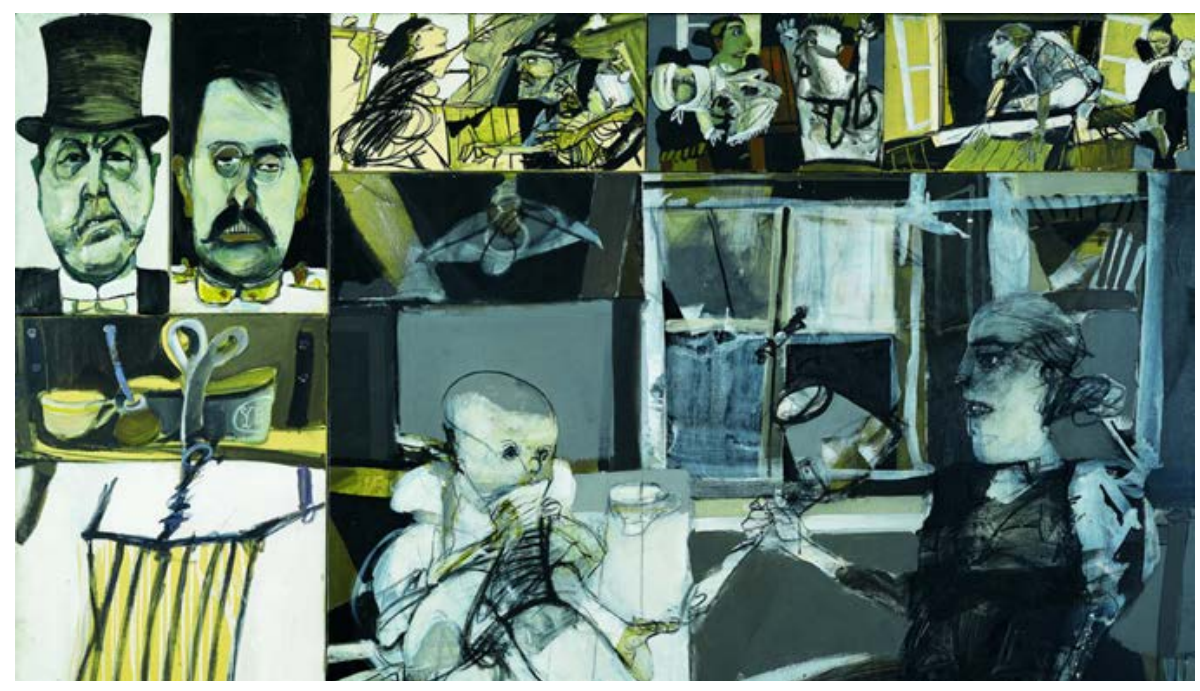

Figura 3. Carlos Alonso, Sin pan y sin trabajo (1966). Colección del artista

La primera obra inspirada en Sin pan y sin trabajo está fechada en 1966 [Figura 3]. Aunque en esta pintura las referencias a De la Cárcova se hacen mucho más explícitas que en la obra de Berni, la composición decimonónica parece estallar en una narración compuesta de numerosos y complejos fragmentos. En la escena principal de la imagen de Alonso se da una interesante inversión de papeles, ya que aquí el lugar del hombre está ocupado por la mujer, que no mira por la ventana (la misma, de hecho, está sellada por manchas de color) sino que dirige su mirada al niño, que está sentado en la mesa masticando una hoja de papel. Ella está firmemente sentada en la silla (la rigidez de su cuerpo contrasta con la dinámica diagonal que traza el obrero en la pintura de De la Cárcova) sosteniendo un cucharón. Una posible narración que anteceda esa situación tiene lugar en la parte superior de la pintura, en la que un friso muestra tres pequeñas imágenes. En ellas sí se hace presente el hombre: sosteniendo el bebé mientras la mujer mira por la ventana, en grito desesperado ante su interlocutora, y atravesando de un salto la ventana (quizás en huida, quizás en firme decisión).

Al igual que Berni, Alonso acude a una gran cantidad de referencias superpuestas para organizar esta pintura, que van desde las propias ilustraciones que realizó para El matadero (la construcción de los personajes y sus ropas, reforzadas por los recuadros del lado izquierdo en los que se ve una parrilla de asado y un juego de mate), hasta los dos retratos que coronan la escena de lado izquierdo y que hacen pensar en los enormes xilocollages de Berni de 1964 - un burgués (bastante parecido a Yrigoyen) y un militar (que resulta inevitable asociar a Onganía) - Las figuras desarmadas y la complejidad de valores de gris y verde recuerdan al Guernico (1937), que se vuelve más latente en el personaje que extiende los brazos al cielo en la segunda figura del friso, y en la lámpara colgante que se incorpora a la escena principal. La alusión a Pablo Picasso traza un puente entre estos dos artistas de fuerte compromiso político, que eligieron la cita y la apropiación como modos de manifestación frecuente.

Pero la vitalidad de la obra de De la Cárcova es tan latente para Alonso, que le permite jugar y desentramar distintos hilos de ella. Dos años después, en 1968, realiza la apropiación Con pan y con trabajo [Figura 4]. En el breve lapso que separó esta obra de su predecesora, Alonso había roto su conexión con el Partido Comunista a raíz de una exposición de retratos de Spilimbergo, que se alejaban de la visión heroica con la que el partido esperaba que se retratara al compañero. 


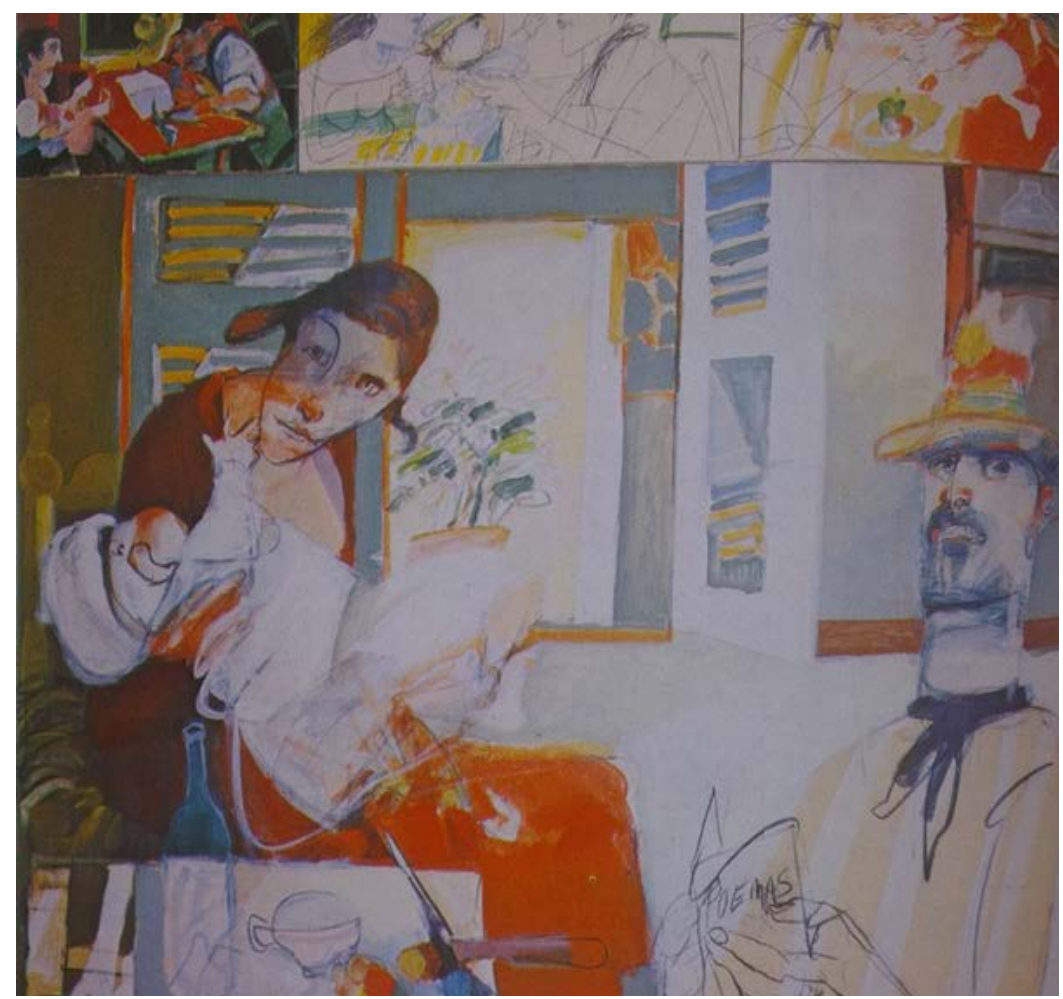

Figura 4. Carlos Alonso, Con pan y con trabajo (1968). Sin datos

En esta nueva recuperación de la obra decimonónica, Alonso repite el recurso de la fragmentación: en el friso superior se dejan ver tres pequeñas situaciones domésticas en las que la mujer y el hombre interactúan con el niño. Quizá la primera de las tres sea la que guarda más similitudes compositivas con la obra de De la Cárcova, solo que aquí el cuerpo masculino traza una diagonal no porque mira por la ventana, sino porque se encuentra dormido sobre la mesa. Sobre la misma también descansa un libro abierto y su herramienta de trabajo, mientras que la mujer contempla la escena. La paleta general es mucho más viva que en la obra de 1966, compuesta por colores de valor alto y de una intensidad lumínica que distancia a esta pintura de su matriz decimonónica. En la escena que culmina el relato, la de mayor tamaño, los dos personajes se encuentran cómodamente sentados: ella con el bebé en brazos; él con un libro de poemas. La mesa sostiene su herramienta de trabajo pero también exhibe comida, y se distingue al fondo de la habitación una ventana abierta (¿0 una puerta?) por la que asoman unas plantas. No hay puños cerrados ni tensión contenida. El dinamismo abre paso a una composición estática, que transmite una sensación de bienestar: hay tiempo para la crianza compartida y para la lectura. En ese contexto tan particular para los latinoamericanos (un año de fuertes movilizaciones populares y estudiantiles) y en medio del gobierno de facto de Juan Carlos Onganía, el conflicto se encuentra aparentemente ausente. Si bien esta obra aumenta su carga simbólica al entenderse como un engranaje dentro de la serie completa, tal vez el hieratismo se vincule con una provocación: los personajes no esconden su rostro sino que levantan la mirada e interpelan al espectador. Ya no se trata de una situación personal, sino que es hora del compromiso político urgente.

\section{EL SUSPIRO DEL PRESENTE: HACIA EL ARTE CONTEMPORÁNEO}

Tanto Berni en la década de los treinta como Alonso en los albores de los setenta tuvieron ideas políticas muy comprometidas y un contacto asiduo - y a la vez conflictivo- con el Partido Comunista. La inserción de sus producciones coincide con situaciones particularmente sensibles a nivel nacional e internacional, que hacen que las artes visuales pongan en duda la tarea del artista como potencial agente de cambio social. Sin pan y sin trabajo se reactivó en ambos momentos, generando resultados atravesados por las circunstancias del presente 
y por el estilo particular de cada artista. Pero la latencia de esta obra no se detuvo en el cambio de siglo: en las últimas décadas, numerosos artistas han vuelto a tomar como fuente la obra de De la Cárcova, sobre todo a partir de la crisis del 2001. En este sentido, Andrea Giunta (2010) recalca la importancia de la ubicación de esta obra en un espacio de legitimación, al declarar que en los últimos años «muchas de las obras capitales del arte argentino alojadas en los museos fueron resemantizadas y reapropiadas desde discursos artísticos contemporáneos con el propósito de acceder a los lados ocultos de esas imágenes» (p. 23).

Innumerable cantidad de artistas, colectivos e incluso grupos no artísticos se han apropiado de Sin pan y sin trabajo en los últimos veinte años, como uno de entre tantos medios posibles para mostrar la vida activa de los conflictos históricos nacionales. Puede mencionarse como caso paradigmático la conocida apropiación de Tomás Espina, un artista que suele trabajar con elementos inestables como el hollín y la pólvora. En su obra Sp y st [Figura 5] se ve un dibujo realizado en carbonilla rojiza sobre una pared blanca (la pared de su estudio), a la que el artista se incorporó físicamente, desnudo. En un trabajo con los roles y el género, Espina modifica los lugares establecidos por De la Cárcova y ubica un personaje masculino del lado de la mujer: la profunda tristeza de la mirada femenina decimonónica es reemplazada en este caso por un melancólico cuerpo desnudo, que mira al trabajador como a través del tiempo. Su gesto curvo y blando contrasta con la rígida tensión del hombre que no puede contenerse en la silla.

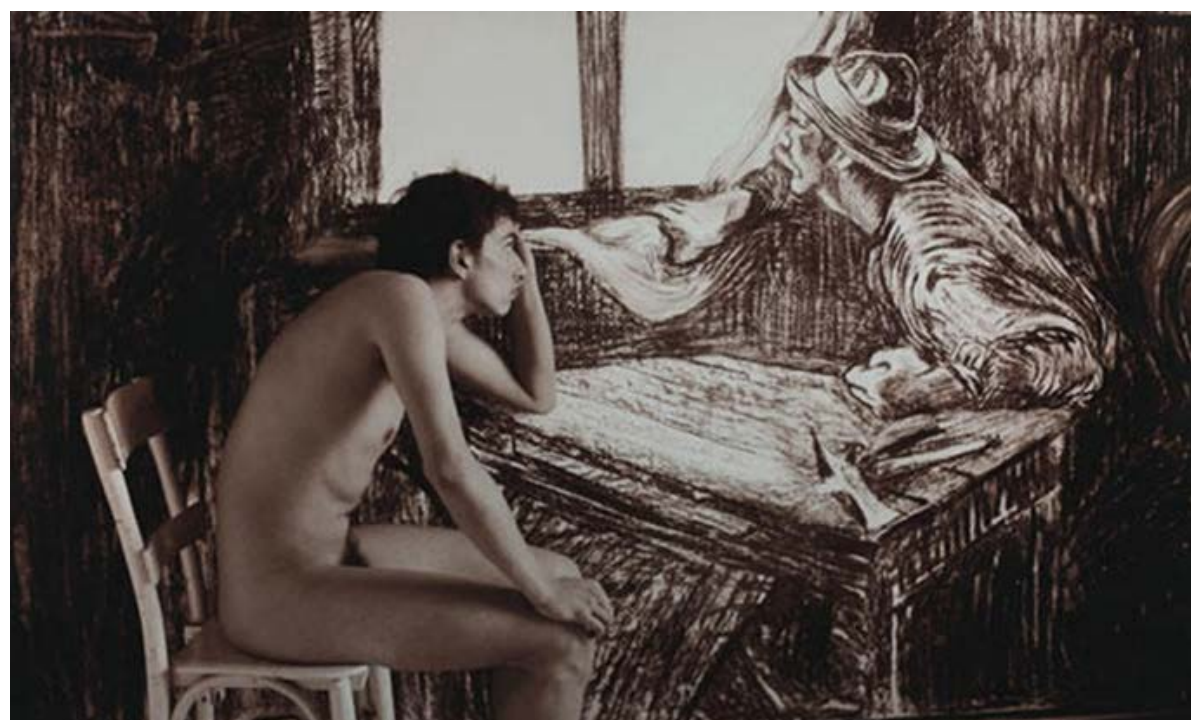

Figura 5. Tomás Espina, Sp y St (2001). Colección Jozami

Espina explicó en una entrevista que la idea original para esta obra era imprimir afiches y pegarlos por la ciudad. En un curioso paralelismo con lo que Berni pretendía para sus obras de gran formato y los espacios que las terminaron albergando, la pieza de Espina no solo no tuvo el formato de afiche, sino que fue presentada al Premio Banco Ciudad en 2002 obteniendo la 2. mención. Desde entonces no ha dejado de formar parte de exhibiciones de arte contemporáneo, tanto en formato impreso como en video, aunque también el artista pudo utilizar el afiche en algunas ocasiones.

Diana Wechsler (2010) entendió a partir de esta imagen que el artista configura visualmente una zona de nuestra memoria cultural y se la apropia en tiempos de crisis para volver a pensar, no solo la condición de aquellos que entonces eran otros, sino la de quienes por medio de la desocupación generalizada de la crisis quedaron al borde del sistema o directamente expulsados de él. Esta otredad no sería la del recién llegado (el inmigrante y proletario del siglo XIX), sino la del que quedó violentamente expulsado del cuadro social con los hechos de 2001. Pero el despojo del cuerpo que aparece en esta imagen podría pensarse también como una reflexión desde el campo artístico sobre los hechos contemporáneos. No como una perplejidad 
ante la realidad, sino como una duda compleja frente a la necesidad de plasmar en imágenes aquello que vuelve a repetirse.

Ante los disturbios de aquel diciembre de 2001, muchos artistas dejaron el trabajo de estudio para salir a las calles, generando movilizaciones de carácter relacional que ligaron el ámbito artístico y el urbano (Giunta, 2009): puede mencionarse el caso del Grupo de Arte Callejero (GAC), que rodeó el edificio del Congreso con las palabras «sin pan y sin trabajo» impresas en una extensa faja. Ese mismo año, el joven artista jorge Pérez realizó un afiche en blanco y negro con la imagen de la obra de De la Cárcova, que acercó a un grupo de piqueteros en el barrio de San Fernando que protestaban ante una fábrica cerrada.

Más recientemente, en 2016, el fotógrafo Javier Gramuglia y el colectivo Trabajadores de la Cultura realizaron una serie en la que recrearon la pintura con el MNBA de fondo. En el marco de las jornadas de lucha La cultura no se achica, la intervención buscaba visibilizar la precarización laboral y los despidos masivos del Ministerio de Cultura. La fuerza simbólica del cuadro se refuerza en este caso a través del juego con el propio edificio que alberga la obra, al que se señaliza no solo como contenedor de la historia del arte, sino también como un espacio de trabajo del que depende la subsistencia de muchas familias. El pasado septiembre de 2018, los ilustradores Damian Scalerandi y Gastón Souto reinterpretaron una vez más la escena de sin pan y sin trabajo para la portada de la famosa revista Fierro, convirtiéndola en una suerte de ficción apocalíptica donde los reclamos sociales se solapan con unos ovnis que sobrevuelan la ciudad, mientras una estampa de Diego Armando Maradona protege la descascarada pared.

Tal vez la síntesis que supo lograr De la Cárcova, al componer una escena tan contundente con una mínima cantidad de elementos, ha colaborado a lo largo del tiempo para que fuera muy simple recrearla: son necesarios dos personajes, un puño, una ventana. La imaginación - y la realidad - se hacen cargo del resto. Las obras que aquí se analizaron tuvieron creadores comprometidos con sus respectivas realidades políticas pero, salvo unas pocas excepciones, se trata de artistas que no traspasaron a la esfera de la acción, sino que se limitaron al problema de la representación. Berni, Alonso e incluso Espina mantuvieron el camino del artista que produce en la intimidad del taller, estableciendo conexiones entre lo que el presente le muestra y lo que ya se vio, entre lo que él vive y las imágenes que su museo imaginario hace resurgir. ¿Cómo representar, otra vez, en el mismo lugar, la pérdida de trabajo, de justicia, de comida, de esperanza? La respuesta para estos artistas parece ser la pregunta misma, escrita sobre una imagen del pasado.

\section{REFERENCIAS}

Alonso, C. (1966). Sin pan y sin trabajo [Pintura]. Recuperado de: https://media.bellasartes. gob.ar/h/gacetillas/prensa_Alonso.pdf

Alonso, C. (1968). Con pan y con trabajo (1968) [Pintura]. Sin datos

Alonso, P. y Cuello, L. (Coords.). (Agosto de 2018). Vido de pintor. Corlos Alonso [Gacetilla de prensa]. Recuperado de www.coleccionfortabat.org.ar/gacetillas/prensaalonsoago18.pdf

Amigo, R. (2010a). El corto siglo de Antonio Berni. En R. Amigo (Coord.), Berni. Narrativas argentinas (pp. 23-62). Ciudad Autónoma de Buenos Aires, Argentina: Museo Nacional de Bellas Artes.

Amigo, R. (2010b). El hurón. Una lectura tendenciosa de algunas obras de los 30. En C. Rossi (Comp.), Antonio Berni. Lecturas en tiempo presente (pp. 17-30). Ciudad Autónoma de Buenos Aires, Argentina: Eudeba. 
Amigo, R. (2017). Un compromiso con el humanismo trascendente. En AA.VV., Berni. Diez obras comentadas (pp. 33-35). Ciudad Autónoma de Buenos Aires, Argentina: EUFyL.

Babino, M. E. (2010). El grupo de Porís. Ciudad Autónoma de Buenos Aires, Argentina: Centro virtual de arte argentino, Ministerio de Cultura del Gobierno de la Ciudad de Buenos Aires.

Benjamin, W. [1936] (2002). Ensoyos. Madrid, España: Editora Nacional.

Berni, A. (1934). Manifestoción [Pintura]. Recuperado de http://malba.org.ar/coleccion-online/?idobra=2001.37

De la Cárcova, E. (1894). Sin pan y sin trabajo [Pintura]. Recuperado de https://www.bellasartes.gob.ar/coleccion/obra/1777/

Delhez, V. (4 de julio de 1933). Los vengadores [Grabado]. Buenos Aires, Argentina: La Prensa.

Didi-Huberman, G. (2017). Por los deseos (fragmentos sobre lo que nos subleva). En Sublevaciones [Catálogo de exposición] (pp. 83-182). Ciudad Autónoma de Buenos Aires, Argentina: EDUNTREF.

Espina, T. (2001). Sp y St [La obra tiene un formato en video y otro en fotografía]. Recuperado de http://www.boladenieve.org.ar/artista/1049/espina-tomas

Fantoni, G. (2017). Una breve deriva. En AA.VV., Berni. Diez obros comentodas (pp. 75-77). Ciudad Autónoma de Buenos Aires, Argentina: EUFyl.

Foster, H. (2004). Archivos de arte moderno. En Diseño y delito y otros diatribas (pp. 65-82). Madrid, España: Akal.

Giunta, A. (2009). Poscrisis. Arte argentino después del 2001. Ciudad Autónoma de Buenos Aires, Argentina: Siglo Veintiuno.

Giunta, A. (2010). Arte y biopolítica. En A. Labaké y F. Farina (Comps.), Poéticas contemporáneas. Itinerarios en las artes visuales en la Argentina de los 90 al 2010 (pp. 23-25). Ciudad Autónoma de Buenos Aires, Argentina: Fondo Nacional de las Artes.

Malraux, A. (1956). El museo imaginario. En Las voces del silencio, visión del arte. Ciudad Autónoma de Buenos Aires, Argentina: Emecé.

Malosetti Costa, L. (2001). Los primeros modernos. Arte y sociedad en Buenos Aires a fines del siglo XIX. Ciudad Autónoma de Buenos Aires, Argentina: Fondo de Cultura Económica.

Malosetti Costa, L. (2010). Ernesto de la Cárcova. Sin pan y sin trabajo. En Arte Siglo XIX. Parte II. Catálogo del Museo Nacional de Bellas Artes (pp. 426-429). Ciudad Autónoma de Buenos Aires, Argentina: Arte Gráfico Editorial Argentino.

Marchesi, M. (2010). Redes de arte revolucionario: el polo cultural chileno-cubano, 1970-1973. A controcorriente 8(1), 120-162. Recuperado de https://acontracorriente.chass.ncsu.edu/index.php/acontracorriente/article/view/486

Marchesi, M. (2014). Imágenes de historia contemporánea. Pintura e historia argentina a finales de los años sesenta: la muerte del Che Guevara y la serie Lo lección de anatomía de Carlos Alonso. En L. Báez Rubí y E. Carreón Blaine (Eds.), Los estatutos de lo imagen, creaciónmanifestoción-percepción. XXXVI Coloquio Internacional de Historio del Arte (pp. 407433). Ciudad de México, México: Universidad Autónoma de México. Recuperado de 
http://www.ebooks.esteticas.unam.mx/files/original/e938173c4a0b9710249dc978b726ada6.pdf

Wechsler, D. (2010). Realidad y utopía. 200 años de arte argentino, una visión desde el presente. Ciudad Autónoma de Buenos Aires, Argentina: Ministerio de Relaciones Exteriores, Comercio Internacional y Culto. 